\title{
Teaching urbanism: the Delft approach
}

Steffen Nijhuis PhD

Assistant Professor, Department of Urbanism, Faculty of Architecture and Built Environment, Delft University of Technology, Delft, The Netherlands (corresponding author: s.nijhuis@tudelft.nl)

Egbert Stolk PhD

Researcher, Department of Urbanism, Faculty of Architecture and

Built Environment, Delft University of Technology, Delft, The Netherlands
MaartenJan Hoekstra MSc, MSa

Lecturer, Department of Urbanism, Faculty of Architecture and

Built Environment, Delft University of Technology, Delft, The Netherlands

The Department of Urbanism at the Faculty of Architecture and Built Environment at the Delft University of Technology has a long tradition in educating generations of internationally oriented designers, planners and researchers in urbanism. Here the domain of urbanism is defined as an interdisciplinary approach that engages in real-world sociocultural, ecological and technological issues affecting urban landscapes, from the perspective of spatial planning and design. Specifically, it combines the disciplines of spatial planning, urban design and landscape architecture, having their own theories, methods and techniques, but also sharing common grounds and being complementary. Urbanism education focuses on specific context-related design tasks, in which knowledge from different disciplines is synthesised into coherent multiscale proposals. This paper aims to elaborate on the foundations of the Delft approach to urbanism education that focuses on the urban landscape as a scale continuum, uses design research and research through design as important teaching and research strategies, and regards mapping and drawing as important tools for thinking. The typical Dutch geographic context and spatial planning traditions are the foundation for this approach. The paper addresses the backgrounds and describes the principles of the present education strategies, learning tactics and examination, and identifies their challenges.

\section{Introduction}

The Department of Urbanism in the Faculty of Architecture and the Built Environment at Delft University of Technology (the Netherlands) has a long history starting in the early 1900s. Since then the Department of Urbanism has made major contributions to academia and the development of the urban environment, while at the same time educating future generations of internationally oriented designers and planners. These urbanists are specialised in future-oriented action and thinking on the development of urban landscapes, responding to the needs of society by mobilising their knowledge and skills towards the creation of more sustainable living environments. The domain of urbanism is understood as a form of practical research that is carried out in the context of application arising from the very work of finding solutions by connecting design, technology and science (cf. Gibbons et al., 1994; Nowotny et al., 2001). Urbanism as such is conceived as an interdisciplinary approach that engages in real-world sociocultural, ecological and technological issues affecting the urban landscape and its green, blue and grey infrastructures. Specifically, it combines the disciplines of spatial planning, urban design and landscape architecture, having their own theories, methods and techniques, but also sharing common grounds and being complementary. Urbanism addresses environmental and societal issues by means of integrative and design-oriented approaches combining spatial planning, urban design and landscape architecture.

This paper aims to elaborate on the typical ways of knowing and working that characterise 'the Delft approach' to urbanism and how this is translated in the educational set-up. However, the paper does not give a detailed description of the full curriculum but outlines the basic elements. The paper starts with introducing the backgrounds and describes the foundations of urbanism as an interdisciplinary approach that focuses on the urban landscape as a scale continuum, uses design research and research through design as important teaching and research strategies, and regards sketching, drawing and mapping as important tools for thinking. Consequently, the principles of education and the general set-up will be outlined, as well as the education strategies, learning tactics and examinations. Finally, the authors identify challenges for the development of urbanism education and give some concluding remarks. 
Teaching urbanism: the Delft approach

Nijhuis, Stolk and Hoekstra

\section{Background and characteristics of urbanism}

\subsection{The urban landscape as objects of study}

The faculty has a long tradition in urbanism dating back to the 1900s with protagonists such as Prof. J.A.G. van der Steur (1865-1945) and Prof. M.J. Granpré Molière (1883-1972) who addressed city and landscape as an integral part of architecture education (de Ruijter, 1983; Steenhuis, 2009). In 1947, urbanism education got an impetus through the appointment of J.H. Froger (1903-1976), Th.K. van Lohuizen (1890-1956) and C. van Eesteren (1897-1988) as professors in urban research and design. The team was augmented with J.T.P. Bijhouwer (1898-1974) as visiting professor in landscape architecture. These professors laid out the foundations of what from the early 1990s onwards was formalised into the Department of Urbanism. Their way of understanding the urban landscape was strongly influenced by their practical experience as they were involved (except for Froger) in the planning and design of parts of the Netherlands in the post-war era with its extensive rebuilding and land-reclamation projects (e.g. IJsselmeerpolders). For example, Van Eesteren and Van Lohuizen created the Amsterdam Extension Plan (AUP) in 1934 (Figure 1), and were driving forces of the fourth CIAM congress in 1933 (Congrès Internationaux d'Architecture Moderne) which is widely regarded as a defining event in Modernist urban planning.

Motivated by the typical Dutch geographic context that consists largely of man-made land below sea level, the urban landscape was conceived as a multiscale phenomenon where buildings, cities and landscapes are inherently connected and was subject to an approach where urban planning, urban design and landscape architecture, as well as civil engineering and landscape ecology were closely linked to each other. Extensive knowledge of the Dutch natural landscape with its particular soil and hydrological conditions, as well as a proper understanding of the cultural landscape with its medieval peat polders, seventeenth century lake-bed polders and water cities stood at the basis of planning and design of new urban landscapes. Urban landscape analysis was operationalised as a tool to develop new effective design strategies that take into account structural elements and structural conditions to articulate the architecture of the urban landscape as a whole. The urbanist's gaze had shifted from the building as a component of a built urban structure to build urban structures as



Figure 1. The AUP 1934 created by Van Eesteren and Van Lohuizen, some of the founding fathers of the Department of Urbanism, is an icon of modernist urban planning and was based on extensive knowledge of the natural and cultural landscape. Detail of the AUP, scale bar added by the authors (map from private collection authors) 
components for sustainable development of the urban landscape (Meyer, 2005). This approach to urbanism gave spatial design a new operational power and acknowledged the urban landscape as an important field of inquiry that is context driven, solution focused and interdisciplinary.

\subsection{Connecting research and design}

Since the 1970s, the Department of Urbanism has emerged as a centre for research and design, focusing on the morphology of urban landscapes (building, city, landscape). Morphological studies use an interpretative research method (also called: hermeneutics), in which knowledge from the urban landscape is acquired through reading and analysis of its physical form, these being the tangible results of physical, biological and sociocultural forces. The form of the urban landscape is regarded a purely evidential system without prepossession regarding the meaning of its evidence, and presupposes a minimum of assumption. This way of understanding the urban landscape was strongly influenced by the work of Italian and British scholars from the 1950s onwards, such as the architects Caniggia (1963) and Muratori (1959), and the geographer Conzen (1960). Later also French schools of thought contributed to this type of thinking through scholars such as Castex et al. (1978). In Delft a blend of these approaches resulted in a morphological approach where building type, plot and urban open space are integrated with the territorial and topographical qualities of landscape, as exemplified by Palmboom
(1987), Steenbergen (1985), Van der Hoeven and Louwe (1985) and Van Voorden (1983) (Figure 2).

This type of research is not only directed towards gaining knowledge on the architecture of the urban landscape, but is also focused on the application of this knowledge in urbanism and the capacity to understand and design spatial compositions and relationships across scales. It is considered a form of design research geared to acquire knowledge about how to satisfy certain requirements, how to perform tasks and it is a form of knowledge that is available to everyone (cf. Cross, 2006). Leupen et al. (1997: p. 18) put it like this: 'If designing is a creative process that produces something that did not exist previously, analysis begins with the outcome of that process and then attempts to get at the underlying ideas and principles. This analysis [...] is predicated on hypothesis, it is not intended to reconstruct the design process'. In this view, the urban landscape is a container of design knowledge, as expressed by its design principles and typologies and can serve as a basis for future design (Nijhuis and Bobbink, 2012). Next to this form of design research in urbanism the design process itself is used as a vehicle to frame spatial problems visually, explore possibilities and to generate solutions. During this process of research through design, the designer uses heuristics, a relatively simple procedure for a complex decision. These heuristics might consist of examples, patterns, analogies, shape grammars or typologies consisting of various elements (Rowe, 1982). Thus for urbanism, research and

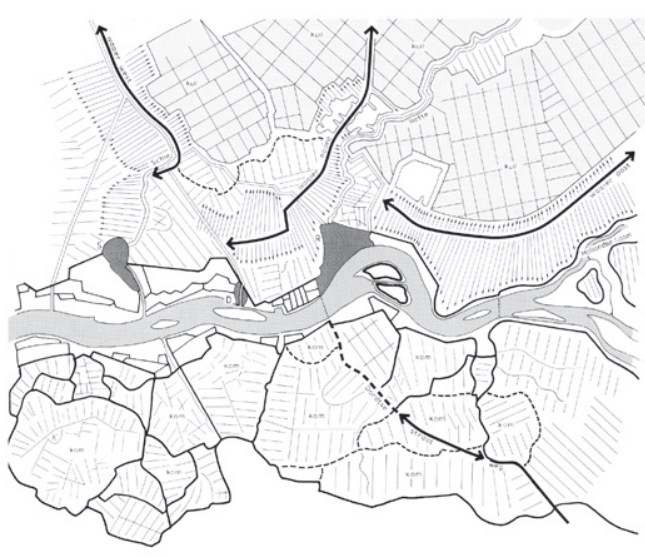

Figure 2. An example of the Delft morphological approach analysing the territorial and topographical qualities of the urban landscape. Left: the structure of the urban landscape around Rotterdam as a result of cultivation of the natural landscape.

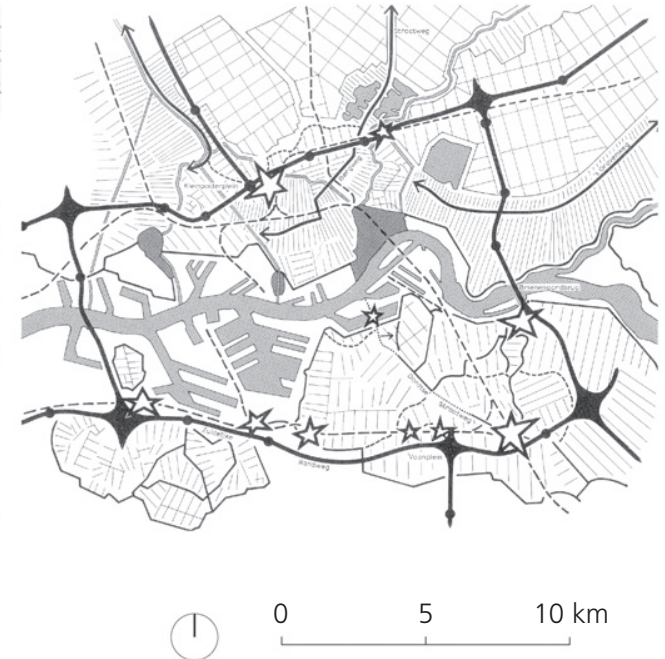

Right: the infrastructure system superimposed. The stars indicate the conflicts between the two. Scale bar added by the authors (image source: Palmboom, 1987) 
design are closely related in several ways and form the basis of the education system.

\subsection{Sketching, drawing and mapping as tools for thinking}

In urbanism, there are three activities in research and design in which visual representations become crucial (Nijhuis, 2013)

- analysis and evaluation of situations, plans or precedents: simplification and selection, relating to the organisation of locational and contextual information in order to gain understanding and acquire design knowledge

- design generation: origination, development and testing of new ideas and information entailing experimentation, transformation, combination and elaboration

- presentation and public communication: effective and comprehensible communication of ideas and/or situations to a wider audience.

As urbanists deal with spatial research and design, it is evident that sketching, drawing and mapping are powerful vehicles for visual thinking and communication. Visual thinking allows to 'digest' information in a rational and systematic way. This is a personal process influenced by the choices and judgments made by the interpreter. At the same time, these findings are made transferable by way of visual representations, which showcase relationships, structures and patterns: visual communication.

By using 'sketches' urbanists externalise their preliminary design ideas: ideas that are still vague and ambiguous. The 'dialectic of sketching' (Goldschmidt, 1991) facilitates the early phases of the design process. In this process, urbanists often use several layers of sketches on top of each other, strengthening this process of discovery (Palmboom and Van den Bout, 2010). Drawings aim to be unambiguous, and are often used in analysing the existing cases (precedent analysis) or in synthesising important design elements, layers or combining different scales (Steenbergen et al., 2008; Stolk and Portugali, 2016). Maps facilitate a spatial understanding of things, concepts, conditions, processes or events in the human/natural world (Harley and Woodward, 1987). Mapping is an activity of constructing and communicating spatial knowledge, and the map is a result of that. Mappings are not one-to-one copies of the existing situation, but their production requires interpretation and reformulation. Map dissection, map comparison and map addition analysis are useful analytical operations (Nijhuis and Pouderoijen, 2014). These operations force the urbanist to make decisions on what and how to map, by making a kind of preliminary design decisions. The resultant maps are considered to be important sources of new knowledge.
To conclude, for urbanists, sketches, maps and drawings are not only the result of the design process, but also important tools for thinking. In parallel with constructing a map or a drawing, the urbanist constructs his/her thoughts. In this dialectic process, the urbanist constantly reinterprets the maps and drawings, which can result in creative insights and the production of new knowledge.

\section{Urbanism education}

\subsection{Five principles for urbanism education}

The Department of Urbanism has an international orientation with staff and $\mathrm{PhD}$ candidates from more than 20 countries in Europe, Asia, Latin America and Africa. In total, 128 people work for the department with a total occupancy of 67.7 full-time equivalent. Most of them are involved in the education programme in varying intensities to ensure the link with the research programmes and the societal relevance of the students' work. About 200 international master students take education in two master tracks of 2 years: an Urbanism MSc and a Landscape Architecture MSc track. Besides, there is a European Postgraduate Master of Urbanism. In general, the education focuses on student-centred teaching methods and specific context-related design tasks, in which knowledge from different disciplines is synthesised into coherent multiscale strategies and interventions. From the background and characteristics of urbanism as described in Section 2, there are five principles that lay out the foundation of the present education at the Department of Urbanism.

\subsubsection{Principle 1: seeing the urban landscape as a multiscale interdisciplinary research object}

The object of research and design in urbanism, the urban landscape, spans a wide range of interrelated scales in time and space that can only be addressed by goal-oriented interdisciplinary research (Figure 3). The urban landscape is complex in nature, which is reflected by several characteristics (Portugali et al., 2012). The urban landscape is an open system, and as such subject to constant change; it is shaped by an ongoing interaction of natural and human processes; and these processes take place on several layers and scales, interacting in a non-linear manner. As a consequence of this complexity, each assignment is highly context sensitive and is difficult to outline from the start.

\subsubsection{Principle 2: gaining theoretical understanding, improving frame creation}

There is a lot of attention in education for understanding the complex nature of the urban landscape. In this respect education facilitates the co-evolution of problem space and solution space (Dorst and Cross, 2001). While generating solutions for a certain problem, new insights might emerge, which require reframing the problem space, which leads to new 


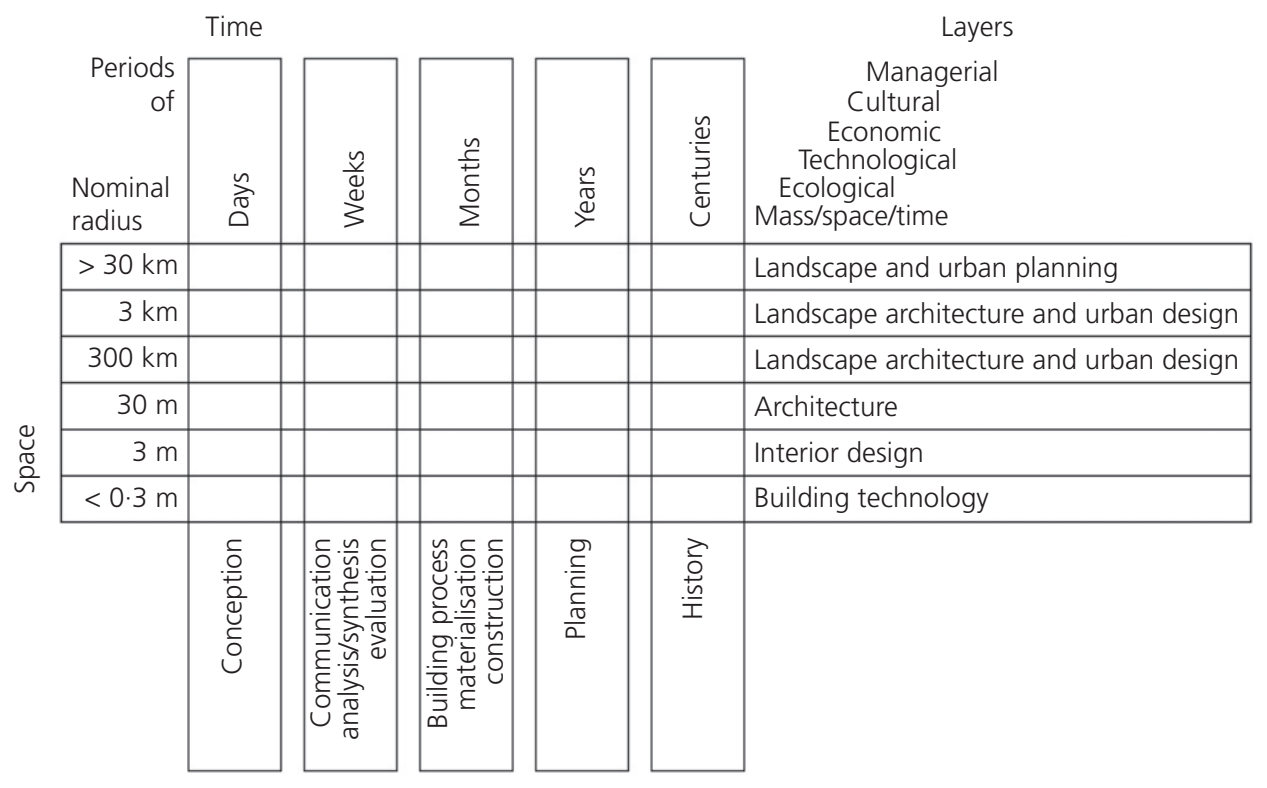

Figure 3. The urban landscape as multiscale interdisciplinary

research object (scheme adapted from: de Jong, 2013)

solutions and so on (Dorst, 2013). This process of co-evolution and creating frames highly depends on the designer and their understanding of the situation. As such, this understanding is not only facilitated by teaching theoretical notions, but also by applying these notions in concrete projects.

\subsubsection{Principle 3: dealing with unpredictability}

Due to the non-linear interactions between the different layers and scales, the urban environment is highly unpredictable. As a consequence, urbanists explore possible and desirable futures in order to support the decision-making processes: futures cannot be predicted, but they can be designed (de Jong, 2013). Besides gaining a theoretical understanding (principle 2), students learn how to use and apply various methods to deal with this unpredictability. For example, students learn to design 'adaptive frameworks' representing the (assumed) stable elements that facilitate processes of change. Next to facilitate emergent processes, these provide a framework for plan implementations.

\subsubsection{Principle 4: designing across scales by visual thinking}

The design medium plays an important role in order to deal with the complex nature of the urban landscape. Maps, drawings and sketches are means to display the interrelations between different layers and scales; they facilitate 'designing across scales' by visual thinking. They complement the use of words and texts, as spatial processes are difficult to capture in words and texts alone. These maps and drawings facilitate the conversation between the urbanist and his/her design medium, and are a means to produce knowledge and understanding about the urban landscape under consideration. Therefore, there is a strong emphasis on research strategies and methods of analysis, such as the layers approach and multiscale mapping techniques.

\subsubsection{Principle 5: exploring the various relations between research and design}

The dynamic nature of the urban landscapes implies that gaining understanding and generating design proposals go hand in hand: there is a co-evolution in the process of research and design, supported by the use of various design media. This co-evolution between research and design can take three forms.

- Research FOR design: Research feeds the design process with the ultimate objective to improve the quality of the designed object and increase its credibility.

- Research THROUGH design: Design is used as a vehicle to make spatial problems visual and spatial, explore possibilities and to generate solutions (Figure 4).

- Research ON design: Research undertaken on existing designs, such as the precedent analysis, as a knowledge basis for future designs.

As a consequence of these five principles, the way professionals/students understand the urban landscape, deal with uncertainty, use design media, conduct research and 
Teaching urbanism: the Delft approach

Nijhuis, Stolk and Hoekstra

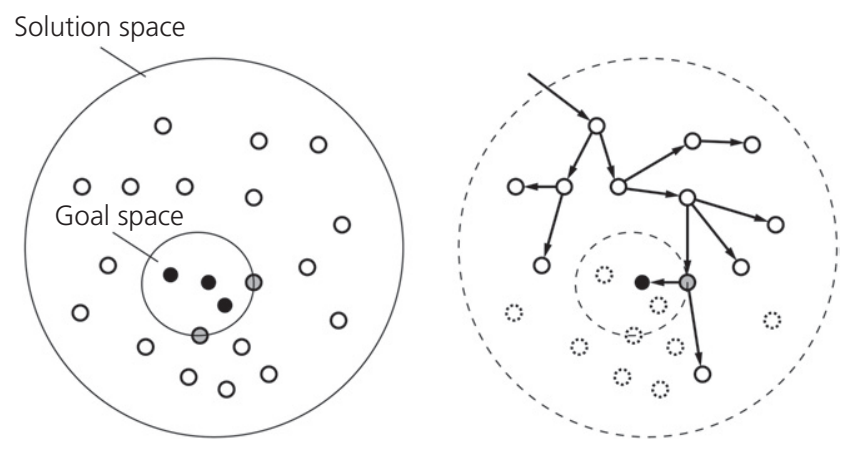

Figure 4. Research through design. While generating solutions for a certain problem, new insights might emerge that require 'reframing' both the goal space and the solution space, which leads to new solutions (adapted from Kalay, 2004)

generate design proposals, is essential for dealing with the urban landscape. This is the challenge in educating urbanists.

\subsection{Project-based learning}

To make these principles operational, the Department of Urbanism education is focused on project-based learning: students explore real-world problems and challenges to acquire knowledge and skills. This is reflected in the general layout of the educational programme which is organised around projects in Research \& Design (R\&D) studios (Figure 5).

The first year consists of four quarters: in the first three quarters the students follow a fixed programme and in the fourth quarter the students follow elective courses. In the first three (thematic) quarters, the R\&D studios are augmented by complementary courses (CC) on theory, methodology and technology, against the background of principle 2. The three R\&D studios focus on projects that address different themes, scales and theoretical approaches, mainly based on principles 1, 3 and 4. These studios, typically consisting of around 15-20 students, are guided by mentors, providing both group and individual supervision. Contentwise, the studio mentors safeguard interaction between the courses on theory and methodology and the R\&D studio, and with that also principles 2 and 5 .

In the second year, the students work on their graduation project, and again follow CC, geared towards supporting the development of their graduation project. In these graduation projects, students are individually guided by two mentors. This process is structured by several obligatory evaluation moments to monitor progress and guarantee the quality of the project. Contentwise, the graduation students are primarily linked to the different research groups in the Department of Urbanism (e.g. Nijhuis and Jauslin, 2013; Nillesen et al., 2016). These groups offer specific activities, such as lectures, workshops and excursions.

\subsection{Active learning methods}

The R\&D studios are about putting knowledge into practice; this knowledge should inform decisions in the design process in a practical context. Therefore on the one hand, students should gain theoretical or declarative knowledge which is public knowledge (e.g. textbooks), and subject to rules of evidence that make it verifiable, replicable and logically consistent. Students have to internalise that knowledge meaningfully (reception learning) (cf. Biggs and Tang, 2011). On the other

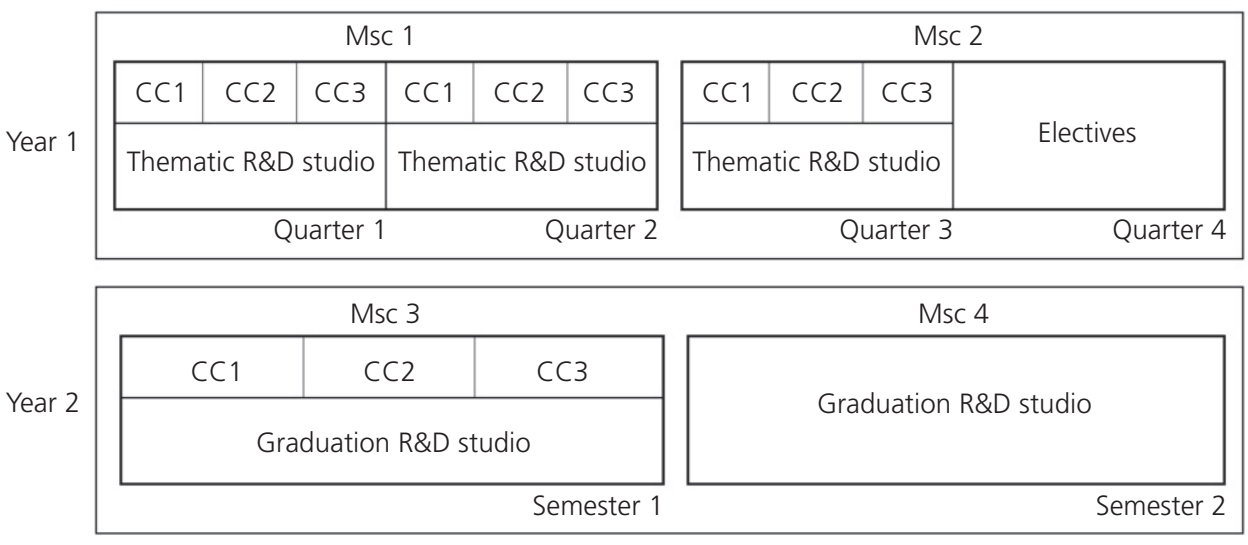

Figure 5. General set-up of the urbanism education that is focused on project-based learning R\&D studio augmented by CC that address related theoretical and methodical aspects, as well as social, ecological, technical issues 


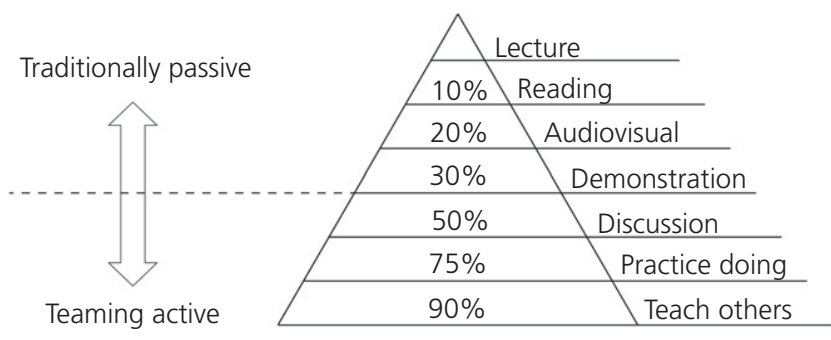

Figure 6. The learning pyramid. Learning activities in relation to average student retention rates. The emphasis in urbanism education in Delft is on teaming active learning activities. (graph adapted from: National Training Laboratories, Bethel, Maine)

hand, learning by doing is an important learning concept in urbanism education. Here functioning knowledge informs action, where the performance is underpinned by understanding. This implies that the student does not only receive content knowledge, but is actively involved in putting knowledge to work. In fact, theoretical and functioning knowledge should be constructed simultaneously. This is facilitated by the general layout of the educational programme.

To construct an effective learning environment and simultaneous development of theoretical and functioning knowledge, different learning activities are used throughout the courses. As exemplified by the learning pyramid (Figure 6), the retention rates of knowledge are different among the learning activities. Therefore, there is a mix of traditionally passive (i.e. lectures, reading texts) and teaming active methods for learning (i.e. studios, discussions/seminars, workshops), activating different sense modalities. In the R\&D studio, the studio mentor facilitatesthe students to use various active learning methods, including giving students control over their own learning process - so that students become their own teacher (Hattie, 2009). This type of learning environment provides for: reflective learning (i.e. learning by teaching, student's self-questioning), relevant learning activity (activating different sense modalities: being active while learning is better than being inactive) and formative feedback and summative assessment (Biggs and Tang, 2011).

\subsection{Constructive alignment}

There are several mechanisms that ensure the quality of the educational set-up and the assessment of the output: constructive alignment and peer-based evaluation. Constructive alignment requires the design of: $(a)$ the 'intended learning outcomes' using a verb indicating a standard of performance and the content to be learned; $(b)$ the 'teaching/learning activities' that address that verb; $(c)$ the 'assessment tasks' that also contain that verb with rubrics that enable one to judge how well the standard of the student's performances meet the criteria (Biggs and Tang, 2011).

Next to the analytical approach related to the use of rubrics, peer-based evaluation remains a crucial mechanism and a constituent element of the education set-up in urbanism to ensure the quality of the process and output (Bowring, 1997; Milburn et al., 2003). In particular, the assessment of the studio work (projects) is necessarily a peer-based evaluation process especially because the output is highly differentiated and interdisciplinary and therefore often hard to judge using rubrics alone. The referee system eliminates the need for a constant checking of the results and theories advanced by others, and thereby allow urbanists to devote themselves to novel and creative inquiries (Zuckerman and Merton, 1971).

\subsection{Two exemplary MSc graduation projects}

The described approach to urbanism education may be best exemplified by MSc graduation projects. In the graduation phase, MSc 3 and 4, the knowledge the students gained by project-based learning and the $\mathrm{CC}$ of the curriculum culminate into the student's proof of competence. Here only two projects from different thematic research groups (respectively: urban fabrics and landscape compositions \& systems) are briefly discussed to illustrate the type of results.

\subsection{1 'Framed space versus free space: degrees of freedom in urbanism' by Sarah Oudenaarden (2014)}

In this MSc graduation project, the differences between space free to plan by the user and controlled space by authorities in urban and landscape design play a central role. The student developed a multiscale design strategy for the urban district Hirzbrunnen, Basel (Switzerland), safeguarding coherence on one hand and flexible infill on the other. In this project, scales are assigned to get a grip on the complexity of the city, to understand the processes and interactions between different scales of the urban fabric. The project is grounded in literature on complexity theory, control hierarchies and the relations between parts and wholes and provided the student with an understanding of the multilayer and multiscale nature of the assignment. By simultaneously developing and applying the theoretical framework in the concrete context of Hirzbrunnen, the student gained understanding of the situation, and synthesised the theoretical insights and contextual knowledge. The project dealt with unpredictability by distributing control on several scales, leaving possibilities for various stakeholders to contribute to the area, while proposing some stable structures for the area as a whole. In this process, visual thinking played a crucial role, not only in designing across scales for the urban district Hirzbrunnen, but also in using diagrams in developing the theoretical framework. Also the various 


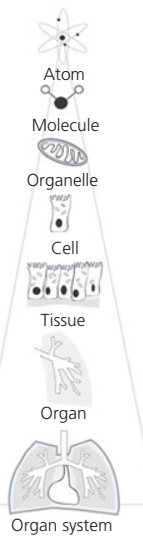

How parts make up wholes

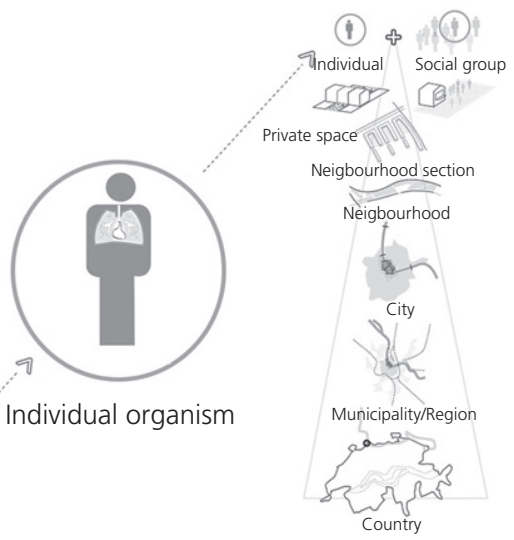

How parts make up a city
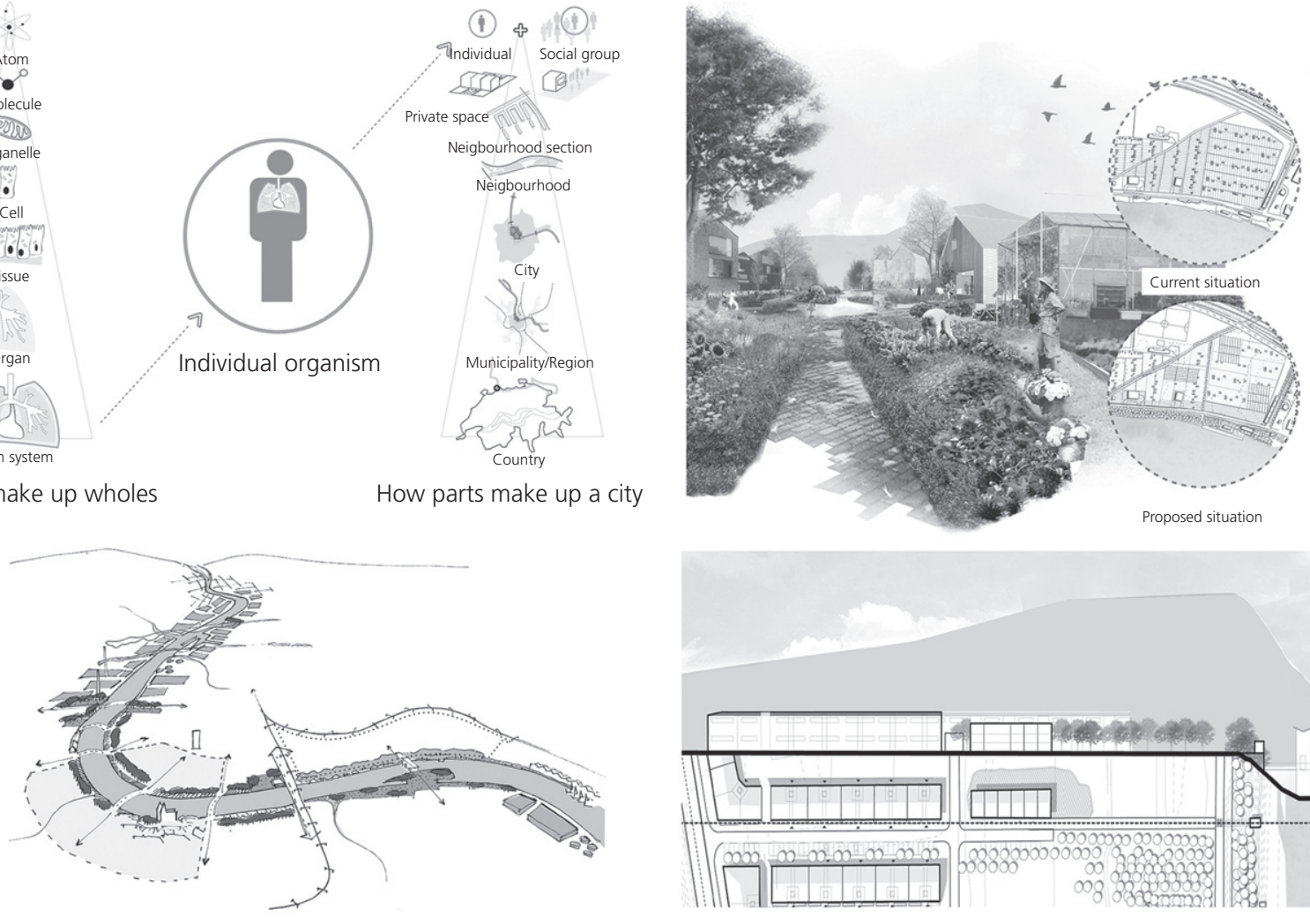

(1) $\stackrel{0}{5} \quad 500 \quad 1000 \mathrm{~m}$

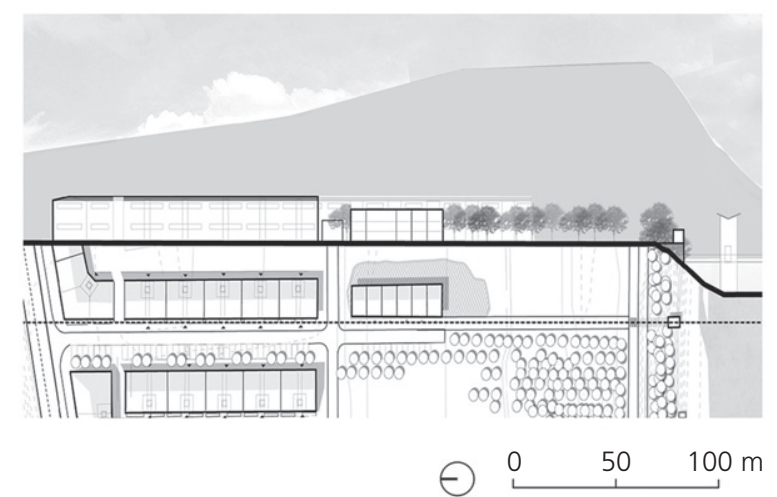

Figure 7. Multiscale design for the urban district Hirzbrunnen, Basel (Switzerland). In the design process visual thinking played a crucial role, using diagrams in developing the theoretical framework (top left) as well exploring possibilities for spatial development through photo-montages (top right), eye-bird views (bottom left) and combinations of plan and section (bottom right) (image source: Oudenaarden, 2014) relations between research and design are explored as exemplified by the co-evolution of theory development and the design for Hirzbrunnen (research for design); the use of various design media, supporting the process of visual thinking (research through design) (Figure 7); and the use of various exemplary projects, ranging from concrete examples to the use of analogies supporting design decisions (research on design).

\subsection{2 'Forum Romanum in Varna. A landscape-based strategy for the integration of marginalised Roma settlements' by Robin de Louw (2015)}

This MSc graduation project provides a strategic socio-spatial development framework for the city of Varna (Bulgaria), as well as a design elaboration of a strategic location, where ethnic enclaves are valued for their diversity and considered as potential activators for underused spaces, redefining the rights and obligations. The work testifies the possibilities of combining landscape architecture and urban design to address social and ecological issues that are elsewhere often treated with bashful reserve. The student used urban landscape infrastructures as a theoretical underpinned design concept, and considered them as armatures for urban development and for facilitating functional, social and ecological interactions. The plan illustrates how a combination of the social and spatial integration of minority groups (Roma) and the development of green-blue and transport networks can result in a feasible spatial development strategy for the city as a whole. This culminates in the architectural elaboration of an operative structure for a Roma enclave that consists of a multipurpose square, multifunctional staircase constructions (with functions such as schools) and agricultural terraces, which are open to multiple uses but also prevent erosion and regulate surface water runoff (research through design) (Figure 8). The plan is thoroughly grounded in the body of knowledge on spatial design, social engineering and landscape ecology (research for design) while applying principles that have proven to work, as exemplified by 

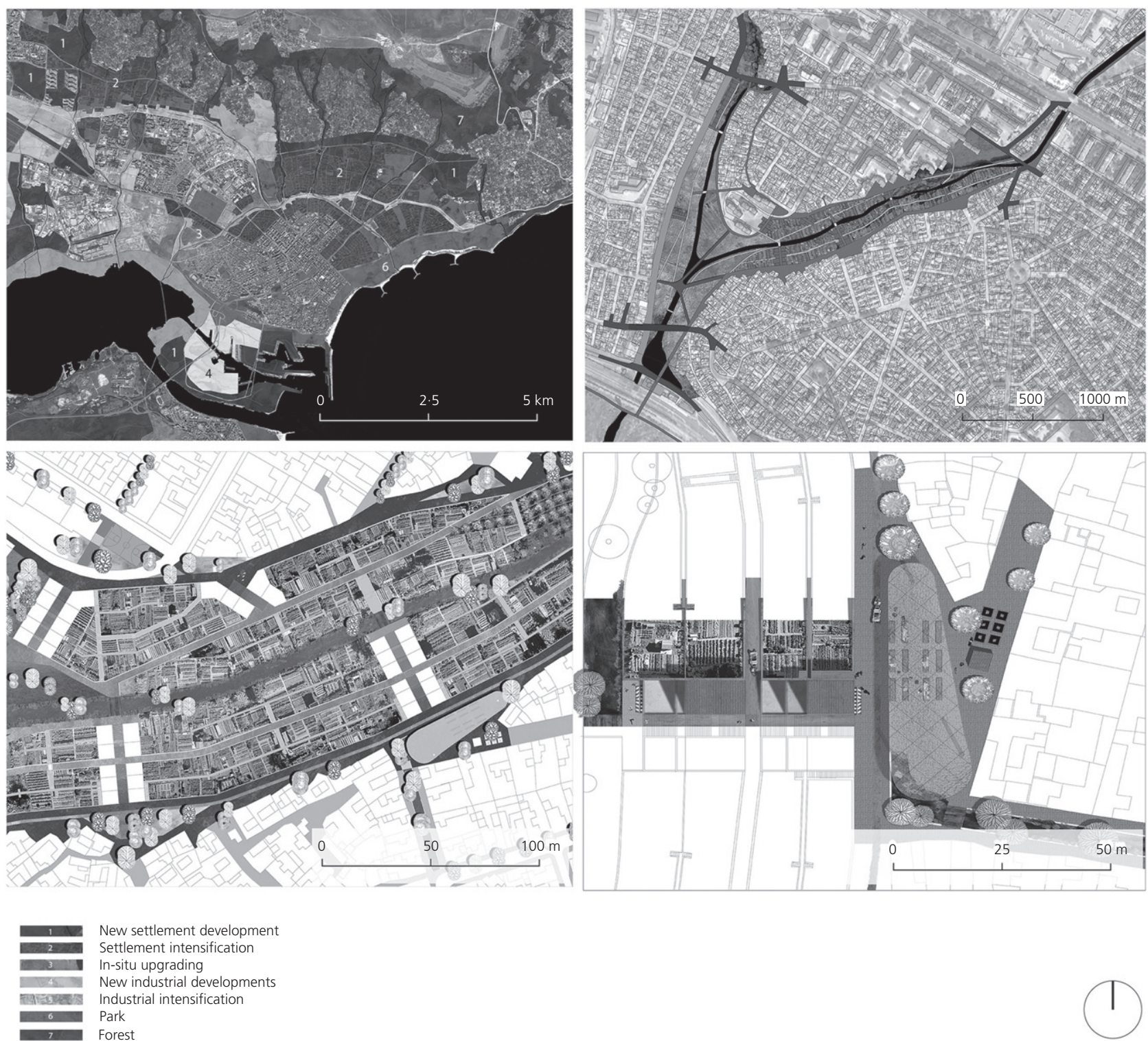

Figure 8. Multiscale design strategy for the city of Varna

(Bulgaria). Green-blue infrastructures and transport infrastructures as armatures for urban development and for facilitating functional, social and ecological interactions (top left). Masterplan for a section (top right) and detailed design elaborations (bottom left and right) (image source: de Louw, 2015) precedents (research on design). Also the work connects real actors and policies and showcases sharp analysis and interpretation of the landscape situation and policies at the European, urban and local level.

Both MSc graduation projects showcase that design assignments are considered multiscale interdisciplinary research objects (principle 1). The projects are grounded in theory (principle 2) and provide for adaptive frameworks for urban development (principle 3), as well as elaborate multiscale design proposals (principle 4), while exploring the various relations between research and design throughout the process (principle 5).

\section{Future challenges}

In general, the education set-up as presented above has proven to be successful in educating urbanism students. Nevertheless, 
Teaching urbanism: the Delft approach

Nijhuis, Stolk and Hoekstra there are several challenges and points for improvement to develop the design-oriented and learning-outcome-based education.

For instance, there is a tension between the development of the foundations of spatial planning, urban design and landscape architecture as independent disciplines with their own histories, approaches and objects of studies, and the development of urbanism as an interdisciplinary domain. As urbanism is slowly developing into an academic disciple in its own right, it is crucial to safeguard the rich and varied background of its origins. At the same time, it is important to stimulate exchange and interaction with relevant research fields such as civil engineering, landscape ecology, geomatics and social sciences in general. In this context, there is a tendency to enforce the connection between the research programme and the education programme. This leads to practical problems, such as synchronising dynamic research projects and planned educational activities. However, even more importantly, it requires studio teachers to stick to the educational programme, while at the same time offering them the possibility to deviate when necessary.

This process should go hand in hand with a shift from teaching to learning: moving from the perspective of the teacher towards student-centred learning models (Biggs and Tang, 2011). This process is supported by a facultywide implementation of the 'University Teaching Qualification' degree. Nevertheless, the actual change to student-centred and learning-outcome-based teaching, and the development of proper and measurable learning objectives is still in its early phase.

In particular in relation to the $\mathrm{R} \& \mathrm{D}$ studios there is a need to describe and develop more specific criteria as a means of evaluating and communicating design qualities. Also more standardised and transparent protocols for evaluation of the results can be incorporated, providing for a more conscious feedback loop. To do so, there is a need to develop a 'designerly way of knowing' (Cross, 2006) for dealing with a complex multiscale urban landscape (Meyer and Nijhuis, 2013; Portugali and Stolk, 2014). Designing in this complex landscape requires appropriate methods and tools that embrace the dynamic nature of the design object. This is a challenge, as students might have difficulties dealing with emergent processes (Chi et al., 2011). The development of dynamic design media, such as simple simulation models (i.e. NetLogo), might be useful to gain an insight into these emergent processes.

In this paper, the authors have presented an overview on the Delft approach to teaching urbanism. This approach emerged out of the specific geographic context and urban planning and design traditions of the Netherlands, and offers a way to study, design and plan the urban landscape in a multiscale and interdisciplinary manner. By engaging the students in real-world sociocultural, ecological and technological problems, the authors aim to prepare them for worldwide challenges related to the urban landscape. By combining theoretical and functional knowledge, and by combining several scales and disciplines in a stimulating learning environment, the authors aim to foster new generations of urbanists.

\section{REFERENCES}

Biggs J and Tang C (2011) Teaching for Quality Learning at University. McGraw-Hill, London, UK.

Bowring J (1997) Research by design: the refereed studio. Landscape Review 3(2): 54-55.

Caniggia G (1963) Lettura di una città: Como. Edizione New Press, Como, Italy.

Castex J, Celeste P and Panerai Ph (1978) Lecture d'une ville: Versailles. Editions du Moniteur, Paris, France.

Chi MT, Roscoe RD, Slotta JD, Roy M and Chasee CC (2011) Misconceived causal explanations for emergent processes. Cognitive Science 36(1): 1-61.

Conzen MRG (1960) Alnwick, Northumberland. A Study in Town-Plan Analysis. George Philip, London, UK.

Cross N (2006) Designerly Ways of Knowing. Springer, London, UK.

de Jong TM (2013) Diversifying Environments through Design. Delft University of Technology, Delft, the Netherlands.

de Louw R (2015) Forum Romanum in Varna. A Landscape-Based Strategy for the Integration of Marginalized Roma Settlements. MSc thesis,

Delft University of Technology, Delft, the Netherlands.

de Ruijter P (1983) Stedebouw-onderwijs 1900-1945. Over de voorgeschiedenis van het onderwijs in stedebouwkunde, landschapsarchitectuur en planologie. Den Haag (in Dutch).

Dorst K (2013) Academic Design. Eindhoven University of Technology, Eindhoven, the Netherlands.

Dorst K and Cross N (2001) Creativity in the design process: co-evolution of problem-solution. Design Studies 22(5): 425-437.

Gibbons M, Limoges C, Nowotny H et al. (1994) The New Production of Knowledge: The Dynamics of Science and Research in Contemporary Societies. SAGE Publications, London, UK.

Goldschmidt G (1991) The dialectics of sketching. Creativity Research Journal 4(2): 123-143.

Harley JB and Woodward D (eds) (1987) The History of Cartography. Vol. I: Cartography in Prehistoric, Ancient and Medieval Europe and the Mediterranean. University of Chicago Press, Chicago, IL, USA. Hattie JAC (2009) Visible Learning. A Synthesis of $800+$ Meta-Analyses on Achievement. Routledge, London, UK. 
Kalay YE (2004) Architecture's New Media. MIT Press, Cambridge, MA, USA.

Leupen B, Grafe C, Körnig N, Lampe M and de Zeeuw P (1997) Design and Analysis. 010 Publishers, Rotterdam, the Netherlands.

Meyer VJ (2005) From plans via projects to perspective. Urban design at Delft University of Technology. In The Territories of the Urbanist (Font A, Corominas M and Sabaté J (eds)). Edicions UPC Barcelona, Barcelona, Spain, pp. 42-51.

Meyer $\mathrm{H}$ and Nijhuis S (2013) Delta urbanism: planning and design in urbanized deltas - comparing the Dutch delta with the Mississippi River delta. Journal of Urbanism 6(2): 160-191.

Milburn LS, Brown RD, Mulley SJ and Hilts SG (2003) Assessing academic contributions in landscape Architecture. Landscape and Urban Planning 64(3): 119-129.

Muratori S (1959) Studi per una operante storia urbana di Venezia. Instituto poligrafico dello Stato, Libreria dello Stato, Rome, Italy (in Italian).

Nijhuis S (2013) New tools. Digital media in landscape architecture. In The Need for Design. Exploring Dutch Landscape Architecture (Vlug J et al. (eds)). Van Hall Larenstein University of Applied Sciences, Velp, the Netherlands, pp. 86-97.

Nijhuis S and Bobbink I (2012) Design-related research in landscape architecture. Journal of Design Research 10(4): 239-257.

Nijhuis S and Jauslin D (2013) Flowscapes. Design studio for landscape infrastructures. Atlantis 23(3): 60-62.

Nijhuis S and Pouderoijen MT (2014) Mapping urbanized deltas. In Urbanized Deltas in Transition (Meyer VJ and Nijhuis S (eds)). Techne Press, Amsterdam, the Netherlands, pp. 10-22.

Nillesen AL, Kothuis B, Meyer H and Palmboom F (2016) Delta Interventions. Design and Engineering in Urban Water Landscapes. Delft University Publishers, Delft, the Netherlands.

Nowotny H, Scott P and Gibbons M (2001) Re-thinking Science: Knowledge and the Public in an Age of Uncertainty.

Polity, Cambridge Malden, MA, USA.

Oudenaarden S (2014) Framed Space vs. Free Space. MSc thesis, Delft University of Technology, Delft, the Netherlands.

Palmboom F (1987) Rotterdam, verstedelijkt landschap. 010 Publishers, Rotterdam, the Netherlands.

Palmboom F and Van den Bout J (2010) Drawing the Ground. Landscape Urbanism Today. Birkhauser, Basel, Switzerland.

Portugali J and Stolk EH (2014) A SIRN view on design thinking - an urban design perspective. Environment and Planning B: Planning and Design 41(5): 829-846.
Portugali J, Meyer H, Stolk E and Tan E (2012) Complexity Theories of Cities Have Come of Age. Springer, Heidelberg, Germany.

Rowe PG (1982) A priori knowledge and heuristic reasoning in architectural design. JAE 36(1): 18-23.

Steenbergen CM (ed.) (1985) Architectuur en landschap. Rationele, formele en picturale enscenering en het situatief ontwerpen. Delft Universitaire Pers, Delft, the Netherlands (in Dutch).

Steenbergen CM, Meeks S and Nijhuis S (2008) Composing Landscapes. Analysis, Typology and Experiments for Design. Birkhäuser, Basel, Boston, Berlin, Switzerland.

Steenhuis M (ed.) (2009) Deining in Delft. Contouren van het architectuur-en stedenbouwonderwijs 1900-1970. Steenhuis Stedebouw, Schiedam, the Netherlands.

Stolk EH and Portugali J (2016) A complexity-cognitive view on scale in urban design. In Complexity, Cognition, Urban Planning and Design (Portugali J and Stolk EH (eds)). Springer, Heidelberg, Germany, pp. 217-235.

Van der Hoeven C and Louwe J (1985) Amsterdam als Stedelijk Bouwwerk. Een morfologische analyse. SUN, Nijmegen, the Netherlands (in Dutch).

Van Voorden FW (1983) Schakels in stedebouw: Een model voor analyse van de ontwikkeling van de ruimtelijke kwaliteiten van 19de-eeuwse stadsuitbreidingen op grond van een onderzoek in Gelderse steden. Walburg Pers, Zutphen, the Netherlands.

Zuckerman H and Merton RK (1971) Patterns of evaluation in science: institutionalisation, structure and functions of the referee system. Minerva 9(1): 66-100.

\section{HOW CAN YOU CONTRIBUTE?}

To discuss this paper, please email up to 500 words to the editor at journals@ice.org.uk. Your contribution will be forwarded to the author(s) for a reply and, if considered appropriate by the editorial board, it will be published as discussion in a future issue of the journal.

Proceedings journals rely entirely on contributions from the civil engineering profession (and allied disciplines). Information about how to submit your paper online is available at www.icevirtuallibrary.com/page/authors, where you will also find detailed author guidelines. 